\title{
The role of hepatitis B surface antibodies in HBV infection, disease and clearance
}

\author{
Nadia Warner*,1, Stephen Locarnini ${ }^{1}$ \& Hui Xu ${ }^{1}$ \\ ${ }^{1}$ Molecular Research \& Development, Victorian Infectious Diseases Reference Laboratory, Doherty Institute, Melbourne, Victoria, \\ Australia \\ *Author for correspondence: Tel.: +61 39342 9344; nadia.warner@vidrl.org.au
}

The clinical sequelae associated with chronic HBV infection is generally regarded as a consequence of an inadequate and inappropriate immune response to active viral replication, predominantly at the T-cell level. However, recent studies on hepatitis B surface antigen (HBsAg)-specific B cells and hepatitis B surface antibody (anti-HB) responses have identified their previously unrecognized role in the pathogenesis of chronic hepatitis B (CHB). These studies have also uncovered novel therapeutic approaches to more effectively target $\mathrm{HBsAg}$ loss and seroconversion, an important end point and regarded as a functional cure. Anti-HBs IgG has also been shown to have multiple direct acting antiviral roles with the Fab component directly blocking viral entry, and release while the Fc component has been linked to antibody dependent cellular cytotoxicity. Likewise, the HBsAg-specific B-cell dysfunctionality can be reversed providing new therapeutic opportunities to achieve functional cure in CHB.

First draft submitted: 31 October 2019; Accepted for publication: 24 March 2020; Published online: 3 June 2020

Keywords: ADCC/CDC • anti-HBs • B-cell dysfunction • immune complexes • neutralizing antibody • nonneutralizing antibody $\bullet$ therapeutic vaccine

Infection with HBV can cause acute, self-limiting or chronic infection in humans [1]. Over 250 million people (approximately 3\% of the world's population) are chronically infected with HBV, representing a very significant public health burden [2]. Unfortunately, approximately $20 \%$ of patients chronically infected with HBV will develop life-threatening sequelae due to chronic HBV infection, including liver cirrhosis and hepatocellular carcinoma (HCC) [3,4]. An effective prophylactic vaccine against HBV is available, and large-scale immunization has greatly reduced the incidence of new infections. In spite of this success, the burden of liver disease in the next few decades will continue to be significant, as there are still vast numbers of unvaccinated individuals that are at risk of infection and the current vaccines only prevents infection in approximately $80 \%$ of individuals that respond to the vaccine. Moreover, despite the development of antivirals that can suppress replication there is no cure for HBV.

In this review, the authors will outline recent developments that have improved the understanding of the virology, immunology and pathogenesis of HBV infection with focus on the interactions of the virus with anti-HBs, the antibody specific for the virus surface antigen and propose new opportunities for research that could lead to a cure for this disease.

\section{The HBV \& subviral particles}

The infectious HBV is comprised of a viral genome packaged inside a core particle, which is then enveloped by the HBV surface proteins, or HBsAg. These surface proteins are responsible for binding and entry into hepatocytes, and also contain the major antigenic epitopes of the virus. Furthermore, a hallmark of human HBV infection is the secretion of very large amounts of noninfectious 'empty' subviral particles (SVP) comprised HBsAg, which can vary in size and shape from 22 to $28 \mathrm{~nm}$ spheres or as variable length tubular filaments of approximately $20 \mathrm{~nm}$ wide [1]. These SVPs are detected in the blood at $>2000$-fold excess over infectious virions, at concentrations of up to $10^{14}$ particles $/ \mathrm{ml}$ which translates to $1-3 \mu \mathrm{g} / \mathrm{ml}$ of total serum protein [1,5], and have been shown not to interfere with or inhibit virion entry [6]. The function of this overproduction of HBsAg is controversial, but current thinking supports the notion that these SVPs act as decoy particles to bind neutralizing anti-HBs antibodies (Abs),

Future 8 Medicine 
reducing the antiviral effects of the host immune response [7,8], facilitating persistence of $\mathrm{HBV}$ in the presence of neutralizing antibodies [9].

\section{Pathogenesis of HBV}

During acute infection in adults, once viremia becomes detectable, intrahepatic replication increases to peak at levels of up to $10^{8}$ to $10^{9}$ viral copies $/ \mathrm{ml}$ in blood, after which these levels gradually decline preceding the onset of clinical hepatitis [10]. At this stage, there is a lack of any detectable lymphoid cellular infiltration, indicating an initial process of noncytolytic clearance of $\mathrm{HBV}$, presumably via cytokine-mediated inhibition of $\mathrm{HBV}$ replication by the cytokines IFN- $\gamma$ and TNF- $\alpha$. These antiviral cytokines are secreted from CD-8+ T cells in the absence of direct destruction of infected cells [11], with virus-specific $\mathrm{CD} 8^{+}$T-cell-mediated responses becoming detectable with the increase in HBV replication. The goals of clearing infected hepatocytes and preventing further intrahepatic spread usually require a combination and co-ordination of both cytolytic and noncytolytic mechanisms. Acute resolving hepatitis $\mathrm{B}$ is considered a robust, co-ordinated adaptive immune response with $\mathrm{CD} 8^{+} \mathrm{T}$ cells mediating clearance of infected cells, B cells secreting neutralizing anti-HBs and CD4 ${ }^{+} \mathrm{T}$ cells supporting effective viral clearance $[10,12]$.

As discussed above, one of the virus-specific factors affecting viral persistence is the continuous production of HBsAg as SVPs in concentrations over 2000-fold higher than that of whole virions [13]. These particles have been shown to promote a state of T-cell anergy and deletion as well as acting as a decoy for HBV-specific humoral immunity [9]. These particles can also directly modulate innate immune signaling pathways including nuclear factor kappa-light chain enhancer of activated B cells (NF-kB) and mitogen-activated protein kinase (MAPK), both of which suppress inflammatory cytokines and interferon stimulated genes transcription which is normally upregulated by Toll-like receptor (TLR) signaling [13-16]. Other virus-specific proteins such as the HBx protein can inhibit proteasomal degradation of viral proteins, thereby reducing HBV antigen presentation [17] while the viral precore/HBeAg can generate tolerance [18] via downregulating TLR-2 expression on hepatocytes, Kupffer cells and peripheral monocytes during the $\mathrm{HBeAg}$-positive phase of $\mathrm{CHB}$ [19]. The $\mathrm{HBeAg} /$ precore protein significantly downregulates expression of co-stimulatory molecules including CD28 on HBV specific CD-8 ${ }^{+} \mathrm{T}$ cells [20] and CD86 on peripheral blood monocytes and Kupffer cells in the liver [20]. The expression of the HBV polymerase protein has been shown to suppress the production of the myeloid differentiation primary response 88 (MYD88) adaptor protein, central to TLR function [21].

In $\mathrm{CHB}$, the effector cells of both the innate and adaptive pathways are dysfunctional as a consequence of chronic immune stimulation which leads to an 'exhaustion' or 'fatigued' phenotype. Compared with those persons with resolved infection, $\mathrm{HBV}$-specific $\mathrm{CD}^{+}$and $\mathrm{CD}^{+}{ }^{+}$-cell response in $\mathrm{CHB}$ patients are significantly diminished. Molecules responsible for suppressing CTL function, such as the programmed death-1 receptor (PD-1), are typically overexpressed on $\mathrm{HBV}$-specific CTLs in patients with $\mathrm{CHB}$ [22,23]. The inhibitory co-stimulatory molecule cytotoxic T-lymphocyte-associated protein 4 (CTLA4) is also upregulated on $\mathrm{CD}^{+} \mathrm{T}$ cells [24] and the positive co-stimulatory ligand $\mathrm{CD} 40$ is downregulated on $\mathrm{CD}^{+} \mathrm{T}$ cells [25]. Collectively, these changes result in suppressed proliferation of $\mathrm{CD}^{+}{ }^{+}$and $\mathrm{CD}^{+}{ }^{+} \mathrm{T}$ cells [26] but increased IL-10 production by $\mathrm{CD} 4^{+} \mathrm{T}$ cells [25].

The role of the humoral immune response in chronic hepatitis $\mathrm{B}(\mathrm{CHB})$ patients has recently been shown to be more important than was previously recognized. Treatment of patients with resolved hepatitis B infection with specific anti-B-cell therapies such as rituximab or ofatumumab can precipitate viral reactivation which can be life threatening [27]. This risk is high (30-80\%), and much higher compared with similarly matched patients treated with traditional immunosuppressive agents $[27,28]$, and persists even after seroconversion to anti-HBs.

In summary, $\mathrm{CHB}$ is a disease characterized by failure to mount a sufficient and co-ordinated adaptive immune response. Traditionally, it has been assumed that the antibody-based immune response to the HBV proteins is aimed at clearance of circulatory HBV particles while the host T-cell response contributes to eliminating the infected hepatocytes [29]. However, the role of anti-HBs in the natural history and pathogenesis of CHB is undergoing re-examination. For example, several reports have described the persistence of HBsAg associated with concomitant anti-HBs in up to $25 \%$ of patients with $\mathrm{CHB}[30,31]$. The mechanism(s) underlying the co-existence of both $\mathrm{HBsAg}$ and anti-HBs either separately or in the form of immune complexes (IC) has not been resolved.

\section{Role \& antiviral function of anti-HBs}

Anti-HBs has been well established as a reliable diagnostic tool in a number of situations. For example, its presence can indicate protective immunity after acute resolved HBV infection, successful vaccination as well as being accepted as a marker of 'functional cure' of chronic HBV infection (HBsAg loss with anti-HBs seroconversion) [32]. The 
anti-HBs contained in hepatitis B immunoglobulin (HBIG) has been shown to be effective in preventing perinatal transmission from infected mothers to their newborns, post exposure prophylaxis following needle-stick injuries, preventing reinfection of orthotropic liver transplants in previously infected recipients, as well as by the success of the universal immunization program using recombinant $\mathrm{HBsAg}$ [33]. As noted above, B-cell depleting drugs used in oncology and rheumatology such as the anti-CD20 antibody rituximab, can result in HBV reactivation in patients with 'resolved' HBV where nuclear HBV cccDNA has persisted as a viral reservoir for decades [34].

However, the mechanisms of anti-HBs protection are not completely understood, although traditional understanding is based on the model of binding HBV particles in the circulation, thus preventing the infection (or re-infection) of hepatocytes. From a 'direct acting antiviral' perspective, the Fab component of the anti-HBs can block entry of HBV into hepatocytes by preventing the interaction between the binding site of Pre-S1 and NTCP. The Fab part of the anti-HBs IgG can also block the interaction between the 'a' determinant of the HBsAg with the low affinity cell receptor HSPG in a pre-NTCP-binding step. These Ab-binding events may interfere with binding via steric hindrance, or by inducing conformational change within the surface proteins.

Recently, in vitro experiments have shown that the Fc effector functions of anti-HBs can be important as well. Anti-HBs were shown to be internalized into hepatocyte-derived cell lines via the Fc neonatal receptor which caused inhibition of the assembly and release of SVPs as well as virions from these cells [35]. The study also revealed that the internalization of anti-HBs, as well as the intracellular neutralization of HBV [35], were mediated via the FcRn receptor. The group further demonstrated specificity by showing that anti-HBs failed to inhibit virus release when cells were transfected with HBV genomes expressing antibody escape mutants, implying the HBsAg-anti-HBs interaction is epitope specific [35]. These data indicate an alternative antiviral function of anti-HBs by blocking viral particle release from cells, in other words, a secretion inhibition effect, in addition to the classical models of clearance of $\mathrm{HBV} / \mathrm{HBsAg}$ from the circulation [36] and blocking of virus entry.

Further support for the role of anti-HBs in HBV clearance comes from a study of individuals who cleared HBV infection during adefovir/tenofovir therapy. Using a 19-plex epitope mapping approach across the HBsAg antigenic 'a' determinant, occupancy of epitopes in loop 1 and loop 2 of the 'a' determinant was detected in those patients who went on to achieve a functional cure, suggesting that anti-HB responses across these regions are required for clearance [37].

\section{HBsAg-specific B-cell dysfunction}

Anti-HBs are usually only detectable in serum after the clearance of serum HBsAg. As introduced above, it has been suggested that anti-HBs could be depleted by the large number of circulating SVPs that greatly outnumber virions. In support of this suggestion is the finding that complexes of anti-HBs with circulating $\mathrm{HBsAg}$ are not recognized by current diagnostic assays, but can be detected in chronically infected patients using more highly sensitive immunoassays [37,38]. However, alternative explanations have been provided to understand this apparent lack of anti-HBs as an HBsAg-specific B-cell dysfunction. When examining the B-cell phenotype (CD27, CD69, CD71, CD86 and CXCR3 expression) and differentiation into immunoglobulin-producing cells in patients with $\mathrm{CHB}$, researchers observed $\mathrm{B}$-cell activation, but not exhaustion in their cohort, and the rate of memory B-cell proliferation and differentiation to plasma cells was low [39]. In another study, B cells from patients with CHB were isolated and demonstrated hyperactivation during the immune activation phase while the expression of the co-stimulatory molecule CD80 and serum anti-HBs were decreased in the immune tolerant, immune activation and immune clearance phases. These defects were reversed in patients who lost $\mathrm{HBsAg}$ and seroconverted [40].

HBsAg is a T-cell-dependent antigen and the production of anti-HBs requires CD4 ${ }^{+}$T-helper cells (Th) [41]. A unique $\mathrm{CD}^{+}$helper subset within the lymphoid follicle, termed the $\mathrm{T}$ follicular helper (Tfh) cells, has been identified and shown to support the development of B cells into antibody producing cells in germinal centers (GC) [42]. Furthermore this Th cell subset is often dysregulated in chronic infections [43] which can often lead to not only aberrant B-cell responses but also disease progression. In a chronic HBV infection tolerant mouse, it was shown that an effective Tfh cell response to HBsAg was required for clearance of HBV [44]. This response was suppressed by Tregs, but could be reversed by Treg depletion, as well as CTLA4 blocking. Importantly, these investigators confirmed an impaired Tfh response to HBsAg in the blood compartment from patients with CHB, indicating a possible new therapeutic approach for treatment of patients with chronic HBV infection.

Two more recent studies have attempted to address the issue of the lack of anti-HBs in acute and chronic HBV infection $[45,46]$. These investigators were able to establish that HBsAg specific B cells are indeed present in acute, chronic and resolved HBV infection in similar frequencies, but only the cells from resolved HBV infection were 
capable of maturing into anti-HBs-secreting cells in vitro. The HBsAg-specific B cells in acute and chronic HBV infection resembled atypical memory B cells that are characterized by low expression of CD21 and CD27, and high expression of inhibitory markers such as PD-1 and T-bet [47], reflecting an 'exhaustion' phenotype. Interestingly, this functional impairment affected the global B-cell population in HBV-infected patients. One of the studies also demonstrated that these atypical memory B cells accumulated in the liver [48] and both groups showed that the functionality of these atypical memory B cells could be partially restored in vitro by specific culture conditions including PD-1 blockade or with the addition of IL-2, IL-21 and CD40 ligand-expressing feeder cells [46,48]. Thus, it can be concluded from these studies that B-cell dysfunction, rather than antibody depletion is the main contributor to the lack of anti-HBs in acute and chronic infection [46,48]. However, such a conclusion does not explain the presence of ICs and co-circulating anti-HBs in CHB patients which is discussed next.

\section{Immune complexes \& co-existing anti-HBs}

Immune complexes (ICs) of HBsAg and anti-HBs have been found in the majority of patients with $\mathrm{CHB}$ who have high viral loads, irrespective of concomitant detection of free anti-HBs [49,50]. Thus, it could be speculated that most people with HBV have some production of anti-HBs, but these are 'mopped up' by the excess amount of HBsAg in the form of SVPs to form immune complexes [51]. As such, expansion of the antibody responses to curative levels has been attempted as a potential therapeutic approach [51]. Furthermore, since anti-HBs-dependent phagocytic HBsAg uptake may modulate presentation of HBsAg-derived epitopes to antigen-specific T cells, understanding the role of various immune cell subsets in the clearance of HBsAg from the circulation is important. Monocytes, $\mathrm{B}$-cells, dendritic cells and neutrophils have been shown to be the major cell populations that internalize $\mathrm{HBs} \mathrm{Ag}$ ICs in patients with $\mathrm{CHB}$ [52].

Despite the abundance of HBsAg-containing SVPs in the sera, the co-occurrence of free, unbound anti-HBs has been reported. The prevalence of this co-existing anti-HBs appears to depend on the assay used for detection. Initial attempts to explain this co-existing free antigen and antibody led to the theory that the antigenic subtype of the HBsAg and anti-HBs were mismatched [53-57]. Co-existing HBsAg and anti-HBs was usually found in patients with high viral replicative activity, leading to the theory that anti-HBs in chronically infected persons had no significant protective, clearing or pathogenic properties, and that B-cell clones encoding high affinity anti-HBs to that individual's own HBsAg would be (somehow) ineffective [50,58].

The advent and widespread use of DNA sequencing led to an alternative explanation; that coexisting free $\mathrm{HBs} A \mathrm{~g}$ and anti-HBs might be driven by the emergence/selection of HBsAg escape variants [59], which are well known to cause reduced or complete loss of anti-HBs binding to HBsAg [59-62]. Lada and colleagues [59] examined mutations in the $\mathrm{S}$ genes from $\mathrm{CHB}$ patients with and without co-existing anti-HBs, and found a significantly increased number of substitutions ( $\sim 10 \%$ in anti-HBs-positive vs $2 \%$ in those without anti-HBs) in the major antigenic region. These authors concluded that concomitant anti-HBs would favor selection of HBsAg mutants. However, this has been challenged by Zhang and colleagues who demonstrated in their cohort that persons with $\mathrm{CHB}$ who were also positive for anti-HBs did not have significantly more substitutions than appropriately matched persons without detectable anti-HBs [62]. This more recent study is from Asia while the study by Lada and colleagues [59] was a European investigation and so HBV genotype might have played a role.

The detection of co-existing HBsAg and anti-HBs during chronic HBV infection could provide the basis for the concept that an anti-HBs response to HBsAg during the course of $\mathrm{CHB}$ might actually contribute to HBV clearance [51,55]. Antigen-antibody IC may enhance the uptake and processing of HBsAg by phagocytic cells, resulting in more effective cross-presentation of $\mathrm{HBsAg}$, stimulating a revitalized cell-mediated immune response [63]. In support of this, it has been demonstrated that it is possible to generate or reactivate effective T-cell responses via formation of IC [63,64]. Not surprising then, the use of a monoclonal antibody (mAb) known as E6F6 enhanced virus-specific CD8 ${ }^{+}$T-cell responses in HBV tolerant mice [65]. These findings were confirmed by another group using a similar mouse model, where these investigators also removed circulating $\mathrm{HBsAg}$ by using a neutralizing anti-HBs $\mathrm{mAb}(\mathrm{Ab}-\mathrm{H})$. Using this antibody based approach, these investigators were able to reduce virus dependent tolerance, re-establish $\mathrm{B}$-cell and $\mathrm{CD}^{+}{ }^{+} \mathrm{T}$-cell responses to subsequent $\mathrm{HBV}$ vaccination with recombinant HBsAg, resulting in anti-HBs seroconversion [66]. This approach has been termed 'passive-active immunization' and was successfully used to treat post-exposure HBV infection in newborns $[67,68]$. This approach could be extended to the chronically infected scenario and could also drive resolution of persistent infection by preventing multiple rounds of infection or re-infection, eventually leading to depletion of the cccDNA pool via the de-novo cccDNA pathway $[1,45]$. 


\section{HBV neutralization, antibody-dependent cell cytotoxic/complement-dependent cytotoxicity}

Viral proteins are recognized as foreign and antibodies are raised against viral components following infection [69,70]. Surprisingly, only a minor fraction of these antibodies have been shown to have direct antiviral activity in vitro, and as such these antibodies are described as (broadly) neutralizing antibodies while the major fraction is referred to as non-neutralizing antibodies [71]. neutralizing activity requires the antibody to be of relatively high affinity and/or specific for exposed structures on the virus surface [72,73]. Such neutralizing antibodies frequently render virions noninfectious by steric hindrance of the interactions of the viral surface protein and its receptor [74,75]. Furthermore, the generalized process of viral entry with enveloped viruses typically requires extensive conformational changes of the viral surface proteins [76,77], the binding of neutralizing antibodies may also prevent viral entry by directly interfering with these conformational changes [78,79].

Two groups of HBV neutralizing antibodies have been identified. The first type comprises that group of antibodies which target specific sites in the 'a' determinant and are capable of neutralizing viral entry and blocking the interaction with the 'pre-receptor' HSPG [80]. As discussed above, during chronic HBV infection these anti-HB antibodies are often compromised by the large excess of circulating SVPs (both spherical and filamentous forms). Furthermore, these MHR-specific anti-HB antibodies have been shown to block HBV/SVP release from the intracellular compartment following their endocytosis into the hepatocyte via the FcRn receptor [35] (Figure 1). Antibodies to this region are generated by the prophylactic $S$-antigen containing vaccines. The second type of neutralizing anti-HB antibodies target the high affinity receptor binding site of the HBV Pre-S1 domain. These antibodies block the binding of virions to the NTCP receptor on the hepatocyte $[81,82]$ thereby preventing infection of hepatocytes (Figure 1).

It is reasonable to conclude that the vast majority of virus-specific antibodies generated in response to viral infection have no neutralizing activity. This may be because they are elicited from virion fragments, or by viral proteins that are released from dying, infected cells $[83,84]$. Non-neutralizing antibodies can also be enlisted against native surface antigens, but to epitopes for which antibody binding does not interfere with viral attachment and entry [85]. These non-neutralizing antibodies bind to surface-accessible epitopes and control viral infection by utilizing the Fc component of the IgG molecule. This then results in activation of the complement system, augmentation of phagocytosis and promotion of antibody-dependent cellular cytotoxicity (ADCC). Thus, anti-HB antibodies can also act through a variety of additional Fc-dependent mechanisms, including the killing and/or phagocytosis of infected cells, clearance of viral and subviral particles and blocking viral entry via Fab recognition of virions. Experiments using the human hepatoma cell line PLC/PRF/5 cells which express HBsAg on its cell surface have shown that targeted cell lysis can occur through complement-dependent cytotoxicity (CDC) as well as an ADCC process in the presence of monoclonal anti-HB antibodies [86]. The degree of complement-mediated lysis of these cells by monoclonal anti-HBs IgM and IgG2a isotypes, was similar and ranged between 12 and 28\% (mean, $20 \%)$. The IgG1 anti-HBs monoclonal had no effect. More recent studies in mouse models of HBV infection using mAbs targeting the 'a' determinant of the antigenic loop of HBsAg (mAb E6F6) [65] and the NTCP-binding site of Pre-S1 (2H5-A14) [87] have shown the ability of these antibodies to control and lower HBV DNA and HBsAg levels. These antiviral effects were abolished when these mAbs were re-engineered with an Fc component (D265A/N297A or DANA) that prevented binding to the Fc Rs. Interestingly, the Pre-S1 mAb 2H5-A14 but not its DANA variant, significantly reduced the levels of cccDNA in the HBV-infected mice probably by blocking multiple rounds of HBV reinfection (the de novo pathway of cccDNA generation). Thus, an antiviral effect of ADCC mediated by natural killer (NK) cells in vitro has been demonstrated [87].

A key consideration for the relative significance of ADCC/CDC mechanisms operating in $\mathrm{CHB}$ is the pattern of $\mathrm{HBsAg}$ and $\mathrm{HBcAg}$ distribution in the hepatocytes. Initial studies using immunofluorescence (IF) staining of liver biopsies demonstrated HBsAg was localized in the cytoplasm and the membranes of the hepatocytes while $\mathrm{HBcAg}$ was found exclusively in the cytoplasm and nucleus [88]. Importantly, HBsAg expression on liver cell membranes was most prominent in the active stage of $\mathrm{CHB}$ including active cirrhosis. These important observations have been extended by other investigators [89] using immunohistochemistry (IHC) approaches. These studies demonstrated a strong correlation between membranous staining of HBsAg on the hepatocyte and the level of HBV DNA in serum [90], but were unable to demonstrate any correlation between the severity of hepatic inflammation and HBsAg membranous expression. This could be due to the nature of the IHC techniques used compared with IF in differences such as tissue fixation and processing. 


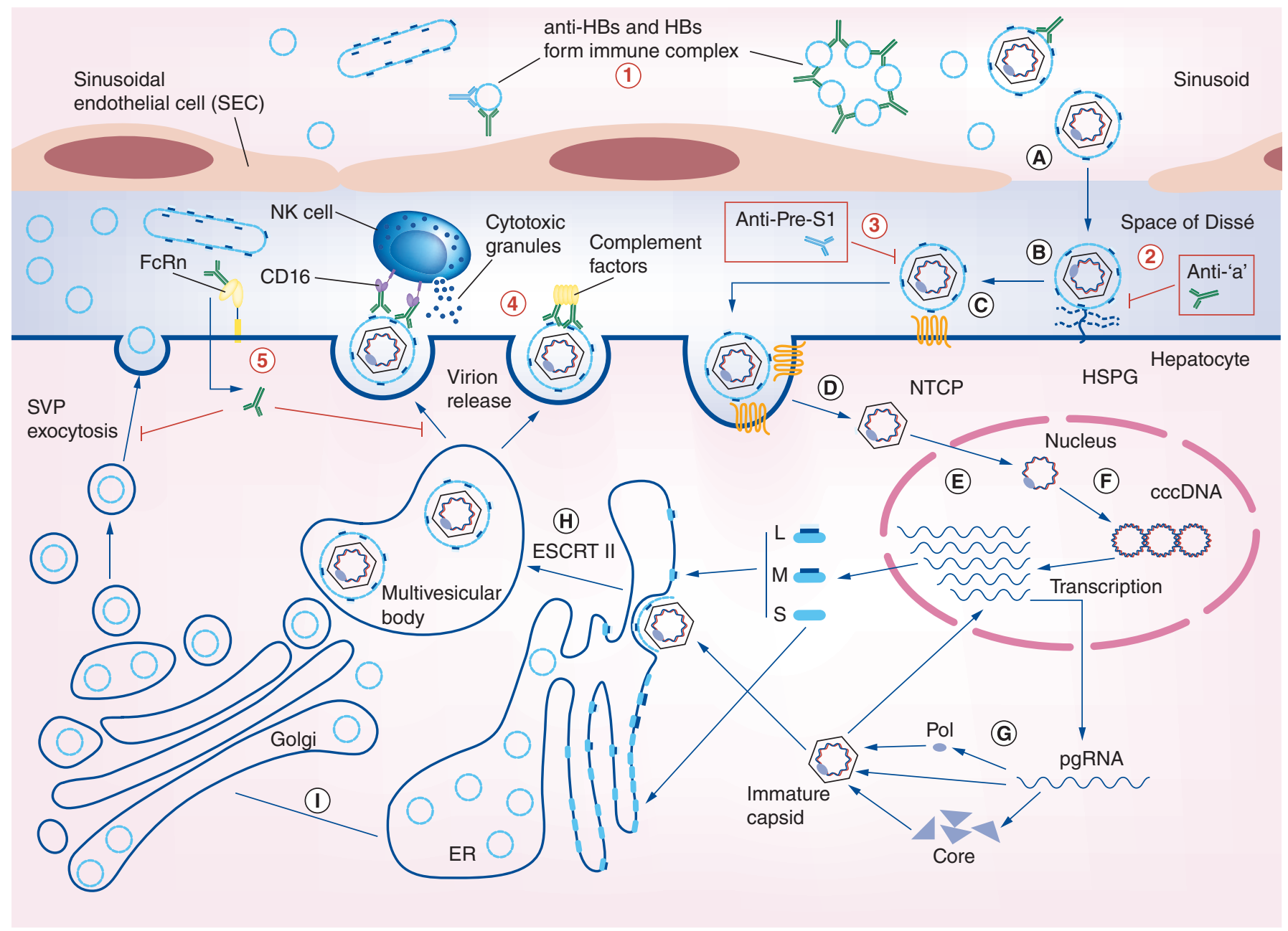

Figure 1. HBV life cycle and the function of anti-HBs. (A) HBV virions circulating in blood stream enter the liver through the sinusoidal system and have contact with hepatocytes possibly by passing through the space of Disse between sinusoidal endothelial cells. (B) HBV binds to the heparan sulphate proteoglycan via its ' $a$ ' determinant of the $\mathrm{S}$ protein; this binding is reversible and low affinity and leads to conformational changes on the surface protein and release the Pre-S1-binding site. (C) The virus establishes stable irreversible binding to NTCP through Pre-S1 on L-protein. (D) The HBV virion enters hepatocytes through endocytosis and releases rCDNA containing nucleocapsids into the cytoplasm. (E) Nucleocapsid is transported into nucleus through the nuclear pore, the core protein dissociates and the virus genome rCDNA is then released. (F) The virus rCDNA is repaired to form the minichromosomal cccDNA, which functions as the major transcriptional template of the virus. (G) The cccDNA is transcribed into various length HBV RNAs including the pgRNA, which is the template for reverse transcription and also functions as a template for core and polymerase proteins. pgRNA is then encapsidated with polymerase and assembled core protein, to form nucleocapsid. (H) The immature capsid is further coated at ER with oligomerised surface proteins, then the matured virion is released through the ESCRT II pathway via the multivesicular body. Alternatively, nucleocapsid can also be directed back to the nucleus to form cccDNA. (I) HBV SVP without nucleocapsids are assembled in the ER but are processed through an ER intermediate compartment, then glycosylated and secreted via Golgi.

Functions of anti-HBs:

1. Can form IC with SVP and virions.

2. The 'a' specific anti-HBs can prevent HBV binding to HSPG.

3. The pre-S1-specific anti-HBs can inhibit HBV binding to NTCP.

4. Anti-HBs can bind to HBsAg presented on the surface of hepatocytes, leading to ADCC, either through activation of complement, or NK cells.

5. Anti-HBs can also be transported into hepatocytes through the FcRn receptor, neutralizing and blocking release of intracellular SVPs and virions.

Finally, it is [91] demonstrated that hepatocytes isolated from patients with $\mathrm{CHB}$ are often found to be covered by immunoglobulin. These investigators demonstrated that in $\mathrm{HBs} A g$-positive chronic liver disease, IgG could be found on the plasma cell membrane and could be linked to increased susceptibility to in vitro NK cell cytotoxicity. This lytic activity for hepatocytes was also shown to be associated with increased severity of histological liver 
damage [91], suggesting a role for ADCC/CDC in the evolution and progression of the liver injury. A later study extended these findings using liver biopsies of $\mathrm{CHB}$ patients and showed that not only $\mathrm{HBcAg}$ and $\mathrm{HBsAg}$ but also the asialoglycoprotein receptor were heavily expressed on the hepatocyte surface and that hepatocyte cytolysis was mediated via complement [92], strongly implying that CDC can also contribute to the injury of HBV-infected hepatocytes.

Collectively, the above observations highlight alternative pathogenic pathways which operate in $\mathrm{CHB}$, generating the potential and opportunity to expand approaches for developing a functional cure of $\mathrm{CHB}$ by exploring the role of envelope-specific neutralizing as well as non-neutralizing anti-HB antibodies.

\section{Therapeutic opportunities for anti-HBs}

Clearance of serum HBsAg is considered a crucial step for restoration of host immunity and functional cure of CHB. To achieve this, both a rapid and potent decrease in the serum HBsAg load with induction of effective (and endogenous) host immunity would be expected to be fundamental and the theoretical ideal approach to achieve functional cure. The 'ingredients' of such a therapeutic approach could include preparations of anti-HBs (potent and neutralizing) and/or therapeutic vaccines which promote Tfh cell, B-cell and $\mathrm{CD} 8^{+} \mathrm{T}$-cell recovery in a co-ordinated response, NK cell based therapy and/or combinations of these including the use of IC-based approaches.

\section{Preparations of anti-HBs}

The clinical applications of human HBIG have been introduced and highlighted earlier. The main antiviral mechanisms of HBIG include preventing HBV entry and re-entry, which appears to not only protect uninfected hepatocytes from infection, but hypothetically could also reduce the level of cccDNA by blocking the de novo pathway. Most clinical investigations have demonstrated that existing levels of circulating HBsAg in patients with $\mathrm{CHB}$ on nucleos(t)ide analog therapy do not change over time, and are almost invariably associated with normalization of serum ALT [93]. These observations indicate the induction of a state of tolerance that could preclude the host from responding to either endogenous viral control or to an immune-based therapeutic clearance. If this is the case, then clearance of circulating HBsAg might be sufficient to reduce the tolerance associated with $\mathrm{CHB}$ in order to enable the host to re-establish protective immune responses, using an immune-based therapeutic. A number of investigators have observed a possible association between the circulating HBsAg level and the state of tolerance in mouse models [66,94]. One group elegantly demonstrated that by removing circulating HBsAg with a monoclonal antibody $(\mathrm{Ab}-\mathrm{H})$ in tolerant mice could indeed reduce tolerance and re-establish both B-cell and $\mathrm{CD}^{+}$T-cell responses to subsequent prophylactic vaccination and indeed produce protective circulating IgG [66]. Furthermore, addition of a TLR agonist resulted in induction of $\mathrm{HBsAg-specific} \mathrm{CD} 8^{+} \mathrm{T}$-cell response capable of clearing HBV from both the serum and liver of these mAb-treated mice. Thus, accumulating evidence is building for the concept that endogenous immune recovery can indeed be achieved by reducing or clearing extracellular HBsAg SVPs with an mAb and subsequent targeted immune-based therapy [66].

Such in vivo studies have been used to (re)-interpret earlier clinical studies of monoclonal anti-HBs therapy in patients with CHB. The first study from Europe in patients not receiving NA therapy and given Tuvirumab, a human $\mathrm{mAb}$ recognizing the 'a' determinant of $\mathrm{HBsAg}$, demonstrated limited efficacy in reducing the $\mathrm{HBs} \mathrm{Ag}$ level [95]. This study treated four patients with Tuvirumab monotherapy and six patients in combination with IFN- $\alpha$ 2b. In those patients with 'low levels' of circulating HBsAg there was a clear decline in HBsAg. In 30\% of patients, the serum ALT levels decreased but the treatment led to the formation of insoluble ICs, resulting in proteinuria in $40 \%$ of the patients. Fortunately, this was reversible on cessation of $\mathrm{mAb}$ therapy. In spite of this, other investigators in Asia have treated patients with monthly HBIG injections but unlike this European study, were on long-term nucleos $(\mathrm{t})$ ide analog therapy, and achieved significant reductions in HBsAg levels of more than $1.0 \mathrm{log}$ $\mathrm{IU} / \mathrm{ml}$ in half the treated patients, but the study numbers were small. Importantly $75 \%$ of these (3 out of 4 ) became anti-HBs positive and no adverse events occurred during the HBIG therapy such as proteinuria/haematuria [96]. In a follow-up of the Tuvirumab study, it is demonstrated that by 3 months after therapy all HBsAg levels had returned to baseline and the monoclonal antibody could no longer be detected [97].

\section{Therapeutic vaccines}

A number of therapeutic vaccines, as either adjunct therapy or as an alternative to long-term NA treatment, have been and are still currently being developed for CHB. One of the first studies used 12 doses of high-dose 
equivalent (100 g) adjuvant-free Engerix-B (recombinant HBsAg-S prepared from yeast) in combination with a novel adjuvant AS02B plus daily Lamivudine for 52 weeks [98]. Disappointingly, the study had no impact on $\mathrm{HBsAg-seroconversion} \mathrm{rates} \mathrm{in} \mathrm{spite} \mathrm{of} \mathrm{the} \mathrm{induction} \mathrm{of} \mathrm{a} \mathrm{vigorous} \mathrm{HBsAg-specific} \mathrm{lymphoproliferative} \mathrm{response,}$ cytokine production as well as anti-HB antibodies in most patients. The latest therapeutic vaccine undergoing clinical evaluation is GS- 4774 from Gilead Sciences, which is a heat-activated, yeast-based T-cell vaccine previously shown to elicit HBV-specific T-cell responses [99]. This vaccine was well tolerated but did not produce significant reductions in the level of serum HBsAg in virally (Tenofovir) suppressed patients with CHB [100]. This pattern of nonresponse is a recurring theme for therapeutic vaccines in $\mathrm{CHB}$ [101,102].

Similarly, clinical trials with peptide vaccines containing highly immunogenic HBc 18-27 and HBV surface based protein vaccines have also shown limited efficacy especially if used as monotherapy $[103,104]$. Later, a vaccine formulation comprising both $\mathrm{HBsAg}$ or $\mathrm{HBcAg}$ particles on a saponin-based adjuvant was evaluated for its ability to stimulate both $\mathrm{T}$ - and B-cell responses in C57BL/6 mice, but any antiviral effects were modest, at best [105]. Other studies demonstrated that immunization with more complex combinations of $\mathrm{HBs} A g$ and $\mathrm{HBcAg}$ antigens as well as with heat shock proteins such as gp96 or ubiquitin could induce robust antiviral T-cell responses resulting in higher levels of IL- 2 and IFN- $\gamma$ as well as a greater percentage of HBsAg-specific CD8 ${ }^{+}$T-cells, anti-HBs and anti-HBc. These responses could be correlated with significant decreases of serum HBsAg and HBV DNA in mouse models $[106,107]$. Thus, it would seem that peptide- and protein-based vaccines combined with adjuvants could effectively activate measurable levels of antiviral immunity [102], but these treatments and effects do not unfortunately translate into an acceptable therapeutic end point such as HBsAg loss.

\section{HBsAg-HBIG immune complex therapeutic vaccine}

To date, the multiple attempts to develop therapeutic vaccines for $\mathrm{CHB}$ have resulted in disappointing outcomes. An alternative strategy led by Wen and colleagues from has focused on using a preformed HBsAg antigen-antibody complex, as a possible therapeutic vaccine candidate for patients with $\mathrm{CHB}$. Their underlying hypothesis is similar to Zhu and colleagues [66] which was based on the premise that patients with $\mathrm{CHB}$ are essentially tolerant to $\mathrm{HBV}$ and this is due to the persistence of HBV antigens especially HBsAg. In order to overcome this defect, the HBsAg was complexed with anti-HBs antibodies at a particular pre-determined ratio [108]. The aim of this approach was to direct $\mathrm{HBs} A g-\mathrm{Ab}$ complexes to antigen presenting cells (APCs) via Fc receptors so that the HBsAg will be processed and presented effectively to $\mathrm{T}$ cells, thereby triggering an immune response against HBV [109]. As supporting background to this study, IC composed of antigen and antibodies have been previously employed in other microbial systems to induce potent antibody responses against microbial proteins [110], and as discussed above, circulating ICs have been found in patients with CHB [111]. The Shanghai group have extended their progress and argued that the crucial difference between circulating IC and the ICs comprised of yeast derived HBsAg and antibodies (abbreviated as YIC) now used in their clinical studies, is that in circulating IC, the anti-HBs antibodies from patients are of low affinity and so cannot bind to circulating HBsAg SVP and clear them from the circulation. In order to overcome this, the anti-HBs used to produce YIC were initially produced in healthy adults who were multiply immunized with yeast-derived recombinant $\mathrm{HBsAg}$, theoretically at least, generating high affinity antibodies that can combine efficiently with HBsAg [112]. A number of trials in animal models [113] as well as clinical studies [108,114] including a Phase III study [115] have been carried out with the new formulations, but unfortunately with mixed results. In the original phase IIa and IIb studies, therapeutic efficacy was demonstrated in patients [108,114], but in the phase III study, the investigators doubled the number of YIC injections compared with the alum control and this appeared to result in overstimulation in the YIC group, reducing the therapeutic efficacy of the vaccine. This was probably due to immune fatigue in the treated patients [115]. A recent in vitro study from the Shanghai group exploring the mechanism of YIC confirmed that the YICs were internalised via the $F_{c}$ receptors (Fc R) of APCs and subsequently transferred through early and late endosomes into the lysosomal compartment [116] for subsequent antigen presentation. YICs administered to mice also increased the populations of IFN- $\gamma$ and TNF- $\alpha$ producing $\mathrm{CD}^{+}$and $\mathrm{CD} 4^{+} \mathrm{T}$ cells, providing a rationale for future clinical development. Further investigations of the clinical efficacy of the YIC approach are needed in order to identify a possible immune therapeutic approach toward functional cure of $\mathrm{CHB}$.

\section{Future perspective}

The recent realization that hepatitis B specific B cells and anti-HBs do indeed have an important role in the pathogenesis of $\mathrm{CHB}$ should result in an important and significant shift of research efforts to address how to 
achieve functional cure. Conventional therapeutic vaccines have, to date been unsuccessful. Understanding the role that anti-HBs can play in achieving clearance of hepatitis B surface antigen from the blood compartment should translate to significant clinical benefit for patients with CHB.

\section{Executive summary}

\section{Chronic HBV}

- The HBV is an enveloped double-stranded DNA virus, which produces a large amount of subviral particles during HBV infection.

- A co-ordinated adaptive immune response of both B cells and T cells are required to achieve virus clearance in acute HBV infection.

- Dysfunction of both T-cell and B-cell responses have been observed during chronic hepatitis B infection.

Anti-HBs

- Anti-HBs can block entry of virus, assembly of subviral particles and secretion/release of subviral particles, induce antibody-dependent cell cytotoxicity of infected cells.

- HBsAg-specific B cells in chronic hepatitis B patients are accumulated in exhausted phenotype and are defect of differentiating into antibody producing cells.

- Immune complexes of anti-HBs with HBsAg and co-existing anti-HBs and HBsAg have been observed in chronic hepatitis $B$ infected patients, their relative function remains elusive.

Therapeutic opportunities

- Anti-HBs can remove HBsAg from blood and reduce tolerance.

- Therapeutic vaccines expressing HBsAg and HBcAg epitopes are being trialed to treat chronic HBV.

- Combinations of anti-HBs and therapeutic vaccines are being developed to treat HBV.

- HBsAg-anti-HBs ICs are being used to treat chronic HBV.

\section{Acknowledgments}

The authors wish to thank T Candy for her excellent editorial work.

Financial \& competing interests disclosure

This work was partly supported by NHMRC Grant, project number APP1127538. S Locarnini receives consulting fees from Gilead Sciences, Biotron and Clear-B Pty Ltd. The authors have no other relevant affiliations or financial involvement with any organization or entity with a financial interest in or financial conflict with the subject matter or materials discussed in the manuscript apart from those disclosed.

No writing assistance was utilized in the production of this manuscript.

\section{Crown copyright}

This work is licensed under Crown copyright protection and licensed for use under the Open Government Licence unless otherwise indicated. Where any of the Crown copyright information in this work is republished or copied to others, the source of the material must be identified and the copyright status under the Open Government Licence acknowledged. Published under CC-BY 4.0 www.nationalarchives.gov.uk/doc/open-government-licence/version/3/@ Crown Copyright.

\section{References}

Papers of special note have been highlighted as: $\bullet$ of interest; $\bullet \bullet$ of considerable interest

1. Gerlich WH. Medical virology of hepatitis B: how it began and where we are now. Virol. J. 10, 239 (2013).

2. Stanaway JD, Flaxman AD, Naghavi M et al. The global burden of viral hepatitis from 1990 to 2013: findings from the Global Burden of Disease Study 2013. Lancet 388(10049), 1081-1088 (2016).

3. Beasley RP. Hepatitis B virus. The major etiology of hepatocellular carcinoma. Cancer 61(10), 1942-1956 (1988).

4. Beasley RP, Lin CC, Chien CS, Chen CJ, Hwang LY. Geographic distribution of HBsAg carriers in China. Hepatology 2(5), 553-556 (1982).

5. Desire N, Ngo Y, Franetich JF et al. Definition of an HBsAg to DNA international unit conversion factor by enrichment of circulating hepatitis B virus forms. J. Viral Hepat. 22(9), 718-726 (2015).

6. Chai N, Chang HE, Nicolas E, Han Z, Jarnik M, Taylor J. Properties of subviral particles of hepatitis B virus. J. Virol. 82(16), 7812-7817 (2008).

7. Carman W, Thomas H, Domingo E. Viral genetic variation: hepatitis B virus as a clinical example. Lancet 341(8841), 349-353 (1993). 
8. Carman WF, Trautwein C, Van Deursen FJ et al. Hepatitis B virus envelope variation after transplantation with and without hepatitis B immune globulin prophylaxis. Hepatology 24(3), 489-493 (1996).

9. Rydell GE, Prakash K, Norder H, Lindh M. Hepatitis B surface antigen on subviral particles reduces the neutralizing effect of anti-HBs antibodies on hepatitis B viral particles in vitro. Virology 509, 67-70 (2017).

-. Shows that subviral particles can reduce the neutralization effect of anti-HBs in an in vitro infection system.

10. Webster GJ, Reignat S, Maini MK et al. Incubation phase of acute hepatitis B in man: dynamic of cellular immune mechanisms. Hepatology 32(5), 1117-1124 (2000).

11. Xia Y, Stadler D, Lucifora J et al. Interferon-gamma and tumor necrosis factor-alpha produced by $\mathrm{T}$ cells reduce the HBV persistence form, cccDNA, without cytolysis. Gastroenterology 150(1), 194-205 (2016).

12. Revill P, Yuan Z. New insights into how HBV manipulates the innate immune response to establish acute and persistent infection. Antivir. Ther. 18(1), 1-15 (2013).

13. Shi B, Ren G, Hu Y, Wang S, Zhang Z, Yuan Z. HBsAg inhibits IFN-alpha production in plasmacytoid dendritic cells through TNF-alpha and IL-10 induction in monocytes. PLoS ONE 7(9), e44900 (2012).

14. Jiang M, Broering R, Trippler M et al. Toll-like receptor-mediated immune responses are attenuated in the presence of high levels of hepatitis B virus surface antigen. J. Viral Hepat. 21(12), 860-872 (2014).

15. Wang $\mathrm{S}$, Chen Z, Hu C et al. Hepatitis B virus surface antigen selectively inhibits TLR2 ligand-induced IL-12 production in monocytes/macrophages by interfering with JNK activation. J. Immunol. 190(10), 5142-5151 (2013).

16. Wu J, Meng Z, Jiang M et al. Hepatitis B virus suppresses toll-like receptor-mediated innate immune responses in murine parenchymal and nonparenchymal liver cells. Hepatology 49(4), 1132-1140 (2009).

17. Seeger C, Mason WS. Hepatitis B virus biology. Microbiol. Mol. Biol. Rev. 64(1), 51-68 (2000).

18. Milich D, Liang TJ. Exploring the biological basis of hepatitis B e antigen in hepatitis B virus infection. Hepatology 38(5), 1075-1086 (2003).

19. Visvanathan K, Skinner NA, Thompson AJ et al. Regulation of Toll-like receptor-2 expression in chronic hepatitis B by the precore protein. Hepatology 45(1), 102-110 (2007).

20. Li X, Kong H, Tian L et al. Changes of costimulatory molecule CD28 on circulating CD8+ T cells correlate with disease pathogenesis of chronic hepatitis B. Biomed. Res. Int. 2014, 423181 (2014).

21. Wu M, Xu Y, Lin S, Zhang X, Xiang L, Yuan Z. Hepatitis B virus polymerase inhibits the interferon-inducible MyD88 promoter by blocking nuclear translocation of Stat1. J. Gen. Virol. 88(Pt 12), 3260-3269 (2007).

22. Boni C, Fisicaro P, Valdatta C et al. Characterization of hepatitis B virus (HBV)-specific T-cell dysfunction in chronic HBV infection. J. Virol. 81(8), 4215-4225 (2007).

23. Fisicaro P, Valdatta C, Massari M et al. Combined blockade of programmed death-1 and activation of CD137 increase responses of human liver T cells against HBV, but not HCV. Gastroenterology 143(6), 1576-1585 e1574 (2012).

24. Schurich A, Khanna P, Lopes AR et al. Role of the coinhibitory receptor cytotoxic T lymphocyte antigen-4 on apoptosis-Prone CD8 T cells in persistent hepatitis B virus infection. Hepatology 53(5), 1494-1503 (2011).

25. Barboza L, Salmen S, Peterson DL et al. Altered T cell costimulation during chronic hepatitis B infection. Cell. Immunol. 257(1-2), 61-68 (2009).

26. Chen CF, Feng X, Liao HY et al. Regulation of T cell proliferation by JMJD6 and PDGF-BB during chronic hepatitis B infection. Sci. Rep. 4, 6359 (2014).

27. Seto WK, Chan TS, Hwang YY et al. Hepatitis B reactivation in patients with previous hepatitis B virus exposure undergoing rituximab-containing chemotherapy for lymphoma: a prospective study. J. Clin. Oncol. 32(33), 3736-3743 (2014).

28. Shouval D, Shibolet O. Immunosuppression and HBV reactivation. Semin. Liver Dis. 33(2), 167-177 (2013).

29. Rehermann B, Nascimbeni M. Immunology of hepatitis B virus and hepatitis C virus infection. Nat. Rev. Immunol. 5(3), 215-229 (2005).

30. Kohno H, Inoue T, Tsuda F, Okamoto H, Akahane Y. Mutations in the envelope gene of hepatitis B virus variants co-occurring with antibody to surface antigen in sera from patients with chronic hepatitis B. J. Gen. Virol. 77(Pt 8), 1825-1831 (1996)

31. Mimms L. Hepatitis B virus escape mutants: "pushing the envelope" of chronic hepatitis B virus infection. Hepatology 21(3), 884-887 (1995).

32. Lok AS, Zoulim F, Dusheiko G, Ghany MG. Hepatitis B cure: from discovery to regulatory approval. Hepatology 66(4), 1296-1313 (2017).

33. Ni YH, Chang MH, Huang LM et al. Hepatitis B virus infection in children and adolescents in a hyperendemic area: 15 years after mass hepatitis B vaccination. Ann. Intern. Med. 135(9), 796-800 (2001).

34. Loomba R, Liang TJ. Hepatitis B reactivation associated with immune suppressive and biological modifier therapies: current concepts, management strategies, and future directions. Gastroenterology 152(6), 1297-1309 (2017). 
35. Schilling R, Ijaz S, Davidoff M et al. Endocytosis of hepatitis B immune globulin into hepatocytes inhibits the secretion of hepatitis B virus surface antigen and virions. J. Virol. 77(16), 8882-8892 (2003).

36. Neumann AU, Phillips S, Levine I et al. Novel mechanism of antibodies to hepatitis B virus in blocking viral particle release from cells. Hepatology 52(3), 875-885 (2010).

37. Walsh R, Hammond R, Yuen L et al. Predicting HBsAg clearance in genotype A chronic hepatitis B using HBsAg epitope profiling: a biomarker for functional cure. Liver Int. 39(11), 2066-2076 (2019).

38. Maruyama T, Mclachlan A, Iino S, Koike K, Kurokawa K, Milich DR. The serology of chronic hepatitis B infection revisited. J. Clin. Invest. 91(6), 2586-2595 (1993).

-• Detects anti-HBs immune complexes using sensitive immunoassays.

39. Oliviero B, Cerino A, Varchetta $S$ et al. Enhanced B-cell differentiation and reduced proliferative capacity in chronic hepatitis $\mathrm{C}$ and chronic hepatitis B virus infections. J. Hepatol. 55(1), 53-60 (2011).

40. Xu X, Shang Q, Chen X et al. Reversal of B-cell hyperactivation and functional impairment is associated with HBsAg seroconversion in chronic hepatitis B patients. Cell Mol. Immunol. 12(3), 309-316 (2015).

41. Milich DR, Mclachlan A. The nucleocapsid of hepatitis B virus is both a T-cell-independent and a T-cell-dependent antigen. Science 234(4782), 1398-1401 (1986).

42. Crotty S. Follicular helper CD4 T cells (TFH). Annu. Rev. Immunol. 29, 621-663 (2011).

43. Ryg-Cornejo V, Ioannidis LJ, Ly A et al. Severe malaria infections impair germinal center responses by inhibiting $\mathrm{T}$ follicular helper cell differentiation. Cell Rep. 14(1), 68-81 (2016).

44. Wang X, Dong Q, Li Q et al. Dysregulated response of follicular helper T cells to hepatitis B surface antigen promotes HBV persistence in mice and associates with outcomes of patients. Gastroenterology 154(8), 2222-2236 (2018).

45. Nassal M. HBV cccDNA: viral persistence reservoir and key obstacle for a cure of chronic hepatitis B. Gut 64(12), 1972-1984 (2015).

46. Salimzadeh L, Le Bert N, Dutertre CA et al. PD-1 blockade partially recovers dysfunctional virus-specific B cells in chronic hepatitis B infection. J. Clin. Invest. 128(10), 4573-4587 (2018).

-. First to characterize HBsAg-specific B cells in patients with chronic HBV.

47. Portugal S, Obeng-Adjei N, Moir S, Crompton PD, Pierce SK. Atypical memory B cells in human chronic infectious diseases: an interim report. Cell. Immunol. 321, 18-25 (2017).

48. Burton AR, Pallett LJ, Mccoy LE et al. Circulating and intrahepatic antiviral B cells are defective in hepatitis B. J. Clin. Invest. 128(10), 4588-4603 (2018).

-. First to characterize HBsAg-specific B cells in patients with chronic HBV.

49. Madalinski K, Burczynska B, Heermann KH, Uy A, Gerlich WH. Analysis of viral proteins in circulating immune complexes from chronic carriers of hepatitis B virus. Clin. Exp. Immunol. 84(3), 493-500 (1991).

50. Dienstag JL. Hepatitis B as an immune complex disease. Semin. Liver Dis. 1(1), 45-57 (1981).

51. Gerlich WH. The enigma of concurrent hepatitis B surface antigen (HBsAg) and antibodies to HBsAg. Clin. Infect. Dis. 44(9), 1170-1172 (2007).

-. Reviews summarized previous findings in term of concurrent $\mathrm{HBsAg}$ and anti-HBs.

52. Tharinger H, Rebbapragada I, Samuel D et al. Antibody-dependent and antibody-independent uptake of HBsAg across human leucocyte subsets is similar between individuals with chronic hepatitis B virus infection and healthy donors. J. Viral Hepat. 24(6), 506-513 (2017).

53. Biswas R, Gerlich W, Schober A, Thomssen R. Determination of antibodies against subtypes of hepatitis B surface antigens (HBsAg) (proceedings). Zentralbl Bakteriol. Orig. A. 235(1-3), 310-315 (1976).

54. Foutch PG, Carey WD, Tabor E et al. Concomitant hepatitis B surface antigen and antibody in thirteen patients. Ann. Intern. Med. 99(4), 460-463 (1983).

55. Shiels MT, Taswell HF, Czaja AJ, Nelson C, Swenke P. Frequency and significance of concurrent hepatitis B surface antigen and antibody in acute and chronic hepatitis B. Gastroenterology 93(4), 675-680 (1987).

56. Tabor E, Gerety RJ, Smallwood LA, Barker LF. Coincident hepatitis B surface antigen and antibodies of different subtypes in human serum. J. Immunol. 118(1), 369-370 (1977).

57. Hayashi J, Noguchi A, Nakashima K, Morofuji M, Kashiwagi S. Frequency of concurrence of hepatitis B surface antigen and antibody in a large number of carriers in Okinawa, Japan. Gastroenterol. Jpn 25(5), 593-597 (1990).

58. Dienstag JL. Concurrent hepatitis B surface antigen and antibody and the clonal selection theory of antibody diversity. Gastroenterology 93(4), 899-902 (1987).

59. Lada O, Benhamou Y, Poynard T, Thibault V. Coexistence of hepatitis B surface antigen (HBs Ag) and anti-HBs antibodies in chronic hepatitis B virus carriers: influence of "a" determinant variants. J. Virol. 80(6), 2968-2975 (2006).

60. Awerkiew S, Daumer M, Reiser M et al. Reactivation of an occult hepatitis B virus escape mutant in an anti-HBs positive, anti-HBc negative lymphoma patient. J. Clin. Virol. 38(1), 83-86 (2007). 
61. Westhoff TH, Jochimsen F, Schmittel A et al. Fatal hepatitis B virus reactivation by an escape mutant following rituximab therapy. Blood 102(5), 1930 (2003).

62. Zhang JM, Xu Y, Wang XY et al. Coexistence of hepatitis B surface antigen (HBsAg) and heterologous subtype-specific antibodies to HBsAg among patients with chronic hepatitis B virus infection. Clin. Infect. Dis. 44(9), 1161-1169 (2007).

63. Wen YM, Mu L, Shi Y. Immunoregulatory functions of immune complexes in vaccine and therapy. EMBO Mol. Med. 8(10), 1120-1133 (2016).

64. Celis E, Chang TW. Antibodies to hepatitis B surface antigen potentiate the response of human T lymphocyte clones to the same antigen. Science 224(4646), 297-299 (1984).

65. Zhang TY, Yuan Q, Zhao JH et al. Prolonged suppression of HBV in mice by a novel antibody that targets a unique epitope on hepatitis B surface antigen. Gut 65(4), 658-671 (2016).

-• A monoclonal anti-HBs was shown to suppress circulating $\mathrm{HBsAg}$ and enhance $\mathrm{CD8}^{+} \mathrm{T}_{\text {-cell }}$ response in mouse models.

66. Zhu D, Liu L, Yang D et al. Clearing persistent extracellular antigen of hepatitis B virus: an immunomodulatory strategy to reverse tolerance for an effective therapeutic vaccination. J. Immunol. 196(7), 3079-3087 (2016).

67. Beasley RP, Hwang LY, Lee GC et al. Prevention of perinatally transmitted hepatitis B virus infections with hepatitis B immune globulin and hepatitis B vaccine. Lancet 2(8359), 1099-1102 (1983).

68. Beasley RP, Hwang LY, Lin CC et al. Hepatitis B immune globulin (HBIG) efficacy in the interruption of perinatal transmission of hepatitis B virus carrier state. Initial report of a randomised double-blind placebo-controlled trial. Lancet 2(8243), 388-393 (1981).

69. Buchmeier MJ, Oldstone MB. Virus-induced immune complex disease: identification of specific viral antigens and antibodies deposited in complexes during chronic lymphocytic choriomeningitis virus infection. J. Immunol. 120(4), 1297-1304 (1978).

70. Maruyama T, Rodriguez LL, Jahrling PB et al. Ebola virus can be effectively neutralized by antibody produced in natural human infection. J. Virol. 73(7), 6024-6030 (1999).

71. Hangartner L, Zinkernagel RM, Hengartner H. Antiviral antibody responses: the two extremes of a wide spectrum. Nat. Rev. Immunol. 6(3), 231-243 (2006).

72. Bachmann MF, Kalinke U, Althage A et al. The role of antibody concentration and avidity in antiviral protection. Science 276(5321), 2024-2027 (1997).

73. Roost HP, Bachmann MF, Haag A et al. Early high-affinity neutralizing anti-viral IgG responses without further overall improvements of affinity. Proc. Natl Acad. Sci. USA 92(5), 1257-1261 (1995).

74. Fleury D, Barrere B, Bizebard T, Daniels RS, Skehel JJ, Knossow M. A complex of influenza hemagglutinin with a neutralizing antibody that binds outside the virus receptor binding site. Nat. Struct. Biol. 6(6), 530-534 (1999).

75. Roben P, Moore JP, Thali M, Sodroski J, Barbas CF3rd, Burton DR. Recognition properties of a panel of human recombinant Fab fragments to the CD4 binding site of gp120 that show differing abilities to neutralize human immunodeficiency virus type 1. J. Virol. 68(8), 4821-4828 (1994)

76. Schibli DJ, Weissenhorn W. Class I and class II viral fusion protein structures reveal similar principles in membrane fusion. Mol. Membr. Biol. 21(6), 361-371 (2004).

77. Skehel JJ, Wiley DC. Receptor binding and membrane fusion in virus entry: the influenza hemagglutinin. Annu. Rev. Biochem. 69, 531-569 (2000).

78. Chan DC, Kim PS. HIV entry and its inhibition. Cell 93(5), 681-684 (1998).

79. Outlaw MC, Dimmock NJ. IgG neutralization of type A influenza viruses and the inhibition of the endosomal fusion stage of the infectious pathway in BHK cells. Virology 195(2), 413-421 (1993).

80. Sureau C, Salisse J. A conformational heparan sulfate binding site essential to infectivity overlaps with the conserved hepatitis B virus a-determinant. Hepatology 57(3), 985-994 (2013).

81. Urban S, Bartenschlager R, Kubitz R, Zoulim F. Strategies to inhibit entry of HBV and HDV into hepatocytes. Gastroenterology 147(1), 48-64 (2014).

82. Yan $\mathrm{H}$, Zhong $\mathrm{G}, \mathrm{Xu} \mathrm{G}$ et al. Sodium taurocholate cotransporting polypeptide is a functional receptor for human hepatitis $\mathrm{B}$ and $\mathrm{D}$ virus. Elife 1, e00049 (2012).

83. Battegay M, Kyburz D, Hengartner H, Zinkernagel RM. Enhancement of disease by neutralizing antiviral antibodies in the absence of primed antiviral cytotoxic T cells. Eur. J. Immunol. 23(12), 3236-3241 (1993).

84. Parren PW, Burton DR, Sattentau QJ. HIV-1 antibody-debris or virion? Nat. Med. 3(4), 366-367 (1997).

85. Lefrancois L, Lyles DS. The interaction of antibody with the major surface glycoprotein of vesicular stomatitis virus. II. Monoclonal antibodies of nonneutralizing and cross-reactive epitopes of Indiana and New Jersey serotypes. Virology 121(1), 168-174 (1982).

86. Shouval D, Wands JR, Zurawski VRJr, Isselbacher KJ, Shafritz DA. Selecting binding and complement-mediated lysis of human hepatoma cells (PLC/PRF/5) in culture by monoclonal antibodies to hepatitis B surface antigen. Proc. Natl Acad. Sci. USA 79(2), 650-654 (1982). 
-• Demonstrates that monoclonal anti-HBs with isotype of IgG2a and IgM, but not IgG1, can lysis HBsAg expressing cell line in the presence of complement.

87. Li D, He W, Liu X et al. A potent human neutralizing antibody Fc-dependently reduces established HBV infections. Elife 6, e26738 (2017).

88. Ray MB, Desmet VJ, Bradburne AF, Desmyter J, Fevery J, De Groote J. Differential distribution of hepatitis B surface antigen and hepatitis B core antigen in the liver of hepatitis B patients. Gastroenterology 71(3), 462-469 (1976).

89. Chu CM, Liaw YF. Intrahepatic distribution of hepatitis B surface and core antigens in chronic hepatitis B virus infection. Hepatocyte with cytoplasmic/membranous hepatitis B core antigen as a possible target for immune hepatocytolysis. Gastroenterology 92(1), 220-225 (1987).

90. Chu CM, Liaw YF. Membrane staining for hepatitis B surface antigen on hepatocytes: a sensitive and specific marker of active viral replication in hepatitis B. J. Clin. Pathol. 48(5), 470-473 (1995).

91. Vergani D, Mieli-Vergani G, Mondelli M, Portmann B, Eddleston AL. Immunoglobulin on the surface of isolated hepatocytes is associated with antibody-dependent cell-mediated cytotoxicity and liver damage. Liver 7(6), 307-315 (1987).

92. Michalak TI, Lau JY, Mcfarlane BM, Alexander GJ, Eddleston AL, Williams R. Antibody-directed complement-mediated cytotoxicity to hepatocytes from patients with chronic hepatitis B. Clin. Exp. Immunol. 100(2), 227-232 (1995).

93. Chen $\mathrm{CH}$, Chiu YC, Lu SN et al. Serum hepatitis B surface antigen levels predict treatment response to nucleos(t)ide analogues. World J. Gastroenterol. 20(24), 7686-7695 (2014).

94. Yang D, Liu L, Zhu D et al. A mouse model for HBV immunotolerance and immunotherapy. Cell Mol. Immunol. 11(1), 71-78 (2014).

95. Van Nunen AB, Baumann M, Manns MP et al. Efficacy and safety of an intravenous monoclonal anti-HBs in chronic hepatitis B patients. Liver 21(3), 207-212 (2001).

96. Tsuge M, Hiraga N, Uchida T et al. Antiviral effects of anti-HBs immunoglobulin and vaccine on HBs antigen seroclearance for chronic hepatitis B infection. J. Gastroenterol. 51(11), 1073-1080 (2016).

97. Heijtink RA, Van Nunen AB, Van Bergen P, Ostberg L, Osterhaus AD, De Man RA. Administration of a human monoclonal antibody (TUVIRUMAB) to chronic hepatitis B patients pre-treated with lamivudine: monitoring of serum TUVIRUMAB in immune complexes. J. Med. Virol. 64(4), 427-434 (2001).

98. Vandepapeliere P, Lau GK, Leroux-Roels G et al. Therapeutic vaccination of chronic hepatitis B patients with virus suppression by antiviral therapy: a randomized, controlled study of co-administration of $\mathrm{HBsAg} / \mathrm{AS} 02$ candidate vaccine and lamivudine. Vaccine 25(51), 8585-8597 (2007).

99. Gaggar A, Coeshott C, Apelian D et al. Safety, tolerability and immunogenicity of GS-4774, a hepatitis B virus-specific therapeutic vaccine, in healthy subjects: a randomized study. Vaccine 32(39), 4925-4931 (2014).

100. Lok AS, Pan CQ, Han SH et al. Randomized phase II study of GS-4774 as a therapeutic vaccine in virally suppressed patients with chronic hepatitis B. J. Hepatol. 65(3), 509-516 (2016).

101. Michel ML, Deng Q, Mancini-Bourgine M. Therapeutic vaccines and immune-based therapies for the treatment of chronic hepatitis B: perspectives and challenges. J. Hepatol. 54(6), 1286-1296 (2011).

102. Wang L, Zou ZQ, Liu CX, Liu XZ. Immunotherapeutic interventions in chronic hepatitis B virus infection: a review. J. Immunol. Methods 407, 1-8 (2014).

103. Heathcote J, Mchutchison J, Lee S et al. A pilot study of the CY-1899 T-cell vaccine in subjects chronically infected with hepatitis B virus. The CY1899 T Cell Vaccine Study Group. Hepatology 30(2), 531-536 (1999).

104. Senturk H, Tabak F, Ozaras R et al. Efficacy of pre-S-containing HBV vaccine combined with lamivudine in the treatment of chronic HBV infection. Dig. Dis. Sci. 54(9), 2026-2030 (2009).

105. Buchmann P, Dembek C, Kuklick L et al. A novel therapeutic hepatitis B vaccine induces cellular and humoral immune responses and breaks tolerance in hepatitis B virus (HBV) transgenic mice. Vaccine 31(8), 1197-1203 (2013).

106. Chen JH, Yu YS, Liu HH et al. Ubiquitin conjugation of hepatitis B virus core antigen DNA vaccine leads to enhanced cell-mediated immune response in BALB/c mice. Hepat. Mon. 11(8), 620-628 (2011).

107. Wang S, Qiu L, Liu G et al. Heat shock protein gp96 enhances humoral and T cell responses, decreases Treg frequency and potentiates the anti-HBV activity in BALB/c and transgenic mice. Vaccine 29(37), 6342-6351 (2011).

108. Xu DZ, Zhao K, Guo LM et al. A randomized controlled phase IIb trial of antigen-antibody immunogenic complex therapeutic vaccine in chronic hepatitis B patients. PLoS ONE 3(7), e2565 (2008).

109. Wen YM. Antigen-antibody immunogenic complex: promising novel vaccines for microbial persistent infections. Expert Opin. Biol. Ther. 9(3), 285-291 (2009).

110. Randall RE, Young DF, Southern JA. Immunization with solid matrix-antibody-antigen complexes containing surface or internal virus structural proteins protects mice from infection with the paramyxovirus, simian virus 5. J. Gen. Virol. 69(Pt 10), 2517-2526 (1988).

111. Michalak T. Immune complexes of hepatitis B surface antigen in the pathogenesis of periarteritis nodosa. A study of seven necropsy cases. Am. J. Pathol. 90(3), 619-632 (1978). 
112. Brown SE, Howard CR, Zuckerman AJ, Steward MW. Affinity of antibody responses in man to hepatitis B vaccine determined with synthetic peptides. Lancet 2(8396), 184-187 (1984).

113. Zheng BJ, Ng MH, He LF et al. Therapeutic efficacy of hepatitis B surface antigen-antibodies-recombinant DNA composite in HBsAg transgenic mice. Vaccine 19(30), 4219-4225 (2001).

114. Yao X, Zheng B, Zhou J et al. Therapeutic effect of hepatitis B surface antigen-antibody complex is associated with cytolytic and non-cytolytic immune responses in hepatitis B patients. Vaccine 25(10), 1771-1779 (2007).

115. Xu DZ, Wang XY, Shen XL et al. Results of a phase III clinical trial with an HBsAg-HBIG immunogenic complex therapeutic vaccine for chronic hepatitis B patients: experiences and findings. J. Hepatol. 59(3), 450-456 (2013).

116. Liu H, Geng S, Wang B et al. Immuno-potentiating pathway of HBsAg-HBIG immunogenic complex visualized. Hum. Vaccin. Immunother. 12(1), 77-84 (2016). 